\title{
Review Article \\ Review of the Wall Temperature Prediction Capability of Available Correlations for Heat Transfer at Supercritical Conditions of Water
}

\author{
Dhanuskodi Ramasamy, Arunagiri Appusamy, and Anantharaman Narayanan \\ Department of Chemical Engineering, National Institute of Technology, Tiruchirappalli, Tamil Nadu 620015, India \\ Correspondence should be addressed to Dhanuskodi Ramasamy; dr193683@gmail.com
}

Received 17 January 2013; Revised 4 August 2013; Accepted 1 September 2013

Academic Editor: S. A. Kalogirou

Copyright (C) 2013 Dhanuskodi Ramasamy et al. This is an open access article distributed under the Creative Commons Attribution License, which permits unrestricted use, distribution, and reproduction in any medium, provided the original work is properly cited.

\begin{abstract}
The validity of the wall temperature predictions by 18 correlations available in the literature for supercritical heat-transfer regimes of water was verified for 12 experimental datasets consisting of 355 data points available in the literature. The correlations were ranked based on criteria like $\%$ data with $<5 \%$ error, $\%$ data with $<10^{\circ} \mathrm{C}$ error and minimum error band in temperature prediction. Details of the best fitting correlations were tabulated. The analysis indicated that for normal heat-transfer conditions, most of the correlations give close predictions. However, at deteriorated heat transfer regimes, only very few prediction points are closer to experimental value. Also, in the ranking process, the first position keeps varying, and no one correlation shall be said as the best for all experiments. Evaluation of the applicability of heat flux to mass-flux-ratio-based prediction of heat-transfer deterioration indicated $75 \%$ agreement. The empirical formulae linking mass flux for the prediction of the starting heat flux for heat-transfer deterioration indicated $58.33 \%$ of agreement. This review indicated that continued precise experimentation covering wide range of parameter conditions near pseudocritical regime and development of correlations is felt necessary for the accurate prediction of supercritical fluid heat transfer.
\end{abstract}

\section{Introduction}

Many applications of supercritical fluids like power engineering, aerospace engineering, and refrigeration engineering have been mentioned in [1-15]. Water at supercritical conditions is largely used in fossil fuel fired boilers [5]. In order to increase the thermal efficiency of nuclear power plants, use of the supercritical water cooling for nuclear reactor is recommended by the Generation IV International Forum (GIF) [14]. Wide uses of supercritical water in power engineering have made the heat transfer of water at supercritical pressure very important and crucial because thorough understanding of the heat transfer is essential for the optimum design and safe operation of the equipment operating at supercritical fluid conditions.

Drastic changes in the properties of fluids at supercritical conditions have been discussed in $[1,3-5,7,8,10-17]$. Although supercritical water does not undergo phase change, it exhibits drastic changes in thermophysical properties that influence heat transfer in a narrow band of temperature or enthalpy. This temperature or enthalpy at which the drastic change occurs is different for each pressure condition. The impact of these property variations on heat transfer has been discussed in [1-21]. As stated in [6], heat transfer to supercritical pressure water and steam was extensively investigated. Goldmann et al. found pseudoboiling phenomenon resembling nucleate boiling, while Shitsman et al. observed that the amount of deterioration depends on the inlet enthalpy and pressure. Ackerman et al. pointed out that a pseudofilm boiling phenomenon can occur in smooth-bore tubes when the pseudocritical temperature of the fluid is between the temperature of the bulk fluid and that of the heated surface. The investigation of Vikrev and Lokshin indicated that the deterioration in horizontal tubes is less than not so sharp as that occurring in vertical tubes for a comparable heat flux.

Shitsman [19] states that, with rising flow, independent of pressure and in proportion to the increase in the heat flux, the temperature distribution diverges more and more from 
the respective theoretical curves which correspond with the usual formula given as follows for convective heat transfer:

$$
\mathrm{Nu}=0.023 \operatorname{Re}^{0.8} \operatorname{Pr}^{0.4}
$$

Many researchers have conducted experiments and published empirical correlations applicable for predicting the heat transfer at supercritical conditions of water. Each correlation is applicable for the specified range of operating parameters. The objective of the present study is to compare the prediction capability of various correlations for the experimental data available in the literature.

\section{Thermophysical Properties of Fluids Near Pseudocritical Conditions}

Heat transfer in convective heat transfer of fluids is influenced by their thermophysical properties for the given conditions. The drastic variations of thermophysical properties near pseudocritical temperatures make the prediction of heat transfer a difficult task. The thermophysical properties at any pressure and temperature or enthalpy condition for many fluids are well established and are provided by NIST/ASME steam property tables based on IAPWS 1997. This is especially important for the creation of generalized correlations in nondimensional form, which allows the experimental data for several working fluids to be combined into one set. The most significant thermophysical property variations occur near the critical and pseudocritical points $[2,7]$.

The thermophysical properties of water at different pressure and temperature, including the supercritical region, can be calculated using the NIST software (1996, 1997). Also, the latest NIST software (2002) calculates the thermophysical properties of different gases and refrigerants for wide ranges of pressure and temperature [7].

Figure 1 displays the trend of thermal conductivity, specific heat, density, and dynamic viscosity with increase in temperature for water at 230 bar taking the peak property in the temperature range as unity and the same at other temperatures as a ratio of the property at the given temperature to the peak value. It is seen that each property has a peak value at one particular temperature. This particular temperature above critical temperature at which the specific heat peaks is termed as pseudocritical temperature. For the selected 230 bar, the pseudocritical temperature is $377.63^{\circ} \mathrm{C}$. The pseudocritical temperature keeps increasing with increase in pressure. With increase in pressure, the peaks in property variation come down. Near critical and pseudocritical temperatures, density and viscosity drop significantly, enthalpy and kinematic viscosity increases sharply, and specific heat, thermal conductivity, and Prandtl's number sharply peak and fall. Similar trends are observed in all other fluids.

\section{Predictive Methods for Heat Transfer at Supercritical Pressures}

Development of analytical models for predicting heat transfers in turbulent flow and at supercritical conditions was not successful due to the complex nature of flow and the abrupt changes in fluid properties. Cheng et al. [8] have plotted the ratio of actual heat-transfer coefficient to heat-transfer coefficient calculated as per (1) with respect to fluid temperature. It is observed that the ratio peaks near pseudocritical temperature at low-heat fluxes, and the same is dipping near pseudocritical temperature at high-heat fluxes. If the Dittus and Boelter correlation is valid, the ratio would be constant at 1 throughout the temperature range. The peaks and dips indicate heat-transfer enhancement and deterioration and the heat-transfer behavior at supercritical condition is different. The wall temperature increase due to the deterioration in heat-transfer coefficient is smooth compared to abrupt increase that is taking place due to boiling crisis in subcritical pressures, and, hence, there is no unique definition for the onset of heat-transfer deterioration so far. For the prediction of heat transfer under such complex conditions, conducting experiments and developing empirical correlations of nondimensional numbers are followed.

Most of the empirical correlations have the general form of a modified Dittus and Boelter equation [8] as given in the following:

$$
\mathrm{Nu}_{x}=C \operatorname{Re}_{x}^{m} \operatorname{Pr}_{x}^{n} F
$$

The correction factor $F$ takes into account the effect of property variation and the entrance effect; that is, $F$ is a function of $\left\{\left(\rho_{w} / \rho_{b}\right),\left((\mathrm{Cp})_{\mathrm{av}} / \mathrm{Cp}\right),(L / D)\right\}$.

A more detailed general form of correlations for calculating heat transfer at super-critical pressures in water and other fluids is given as follows [7]:

$$
\begin{aligned}
\mathrm{Nu}_{t, x}= & C_{1} \operatorname{Re}_{t, x}^{m 1} \operatorname{Pr}_{t, x}^{m 2}\left(\frac{\rho_{t}}{\rho_{t}}\right)_{x}^{m 3}\left(\frac{\mu_{t}}{\mu_{t}}\right)_{x}^{m 4}\left(\frac{k_{t}}{k_{t}}\right)_{x}^{m 5} \\
& \times\left(\frac{(\mathrm{Cp})_{\mathrm{av}, t}}{\mathrm{Cp}_{t}}\right)_{x}^{m 6}\left(1+C_{2}\left(\frac{D_{\mathrm{hy}}}{L_{h}}\right)\right)_{x}^{m 7} .
\end{aligned}
$$

The subscript " $t$ " in (3) refers to either wall temperature or bulk fluid temperatures or average of wall and bulk fluid temperature or their combinations. Around 18 such equations proposed by various authors as given in $[1,3-5,7,8,11,12,15$, $19,20]$ are listed as (B.1) to (B.18) in Table 1.

\section{Comparison of the Wall Temperature Predictions of Different Correlations}

In order to evaluate the prediction capability of the various correlations listed in Table 1, the wall temperature data along with the operating conditions given in the literature $[3,7,10,12,14,15,18]$ were used. Twelve experimental wall temperature datasets available in these literatures were considered. The test parameters and tube inner diameter applicable for each graph were collected. An excel macroprogram was developed for computing wall temperature as per different correlations. X steam excel version of IAPWS 1997 was used for steam properties. Wall temperatures for these experimental conditions containing 355 data points were calculated using 18 correlations. Absolute and percentage temperature deviations of prediction by each correlation for 
TABLE 1: List of correlations used for comparing supercritical water heat transfer in vertical pipe.

\begin{tabular}{|c|c|c|c|}
\hline $\begin{array}{l}\text { Equation } \\
\text { no. }\end{array}$ & $\begin{array}{l}\text { Name of } \\
\text { correlation }\end{array}$ & Correlation & Conditions \\
\hline $\begin{array}{l}\text { Equation } \\
\text { (B.1) }\end{array}$ & $\begin{array}{c}\text { Dittus and } \\
\text { Boelter (1930) }\end{array}$ & $\begin{aligned} \mathrm{Nu}_{b}= & 0.023 \operatorname{Re}_{b}^{0.8} \operatorname{Pr}_{b}^{0.4} \\
& {[8,13,19] }\end{aligned}$ & $\begin{array}{l}\text { Valid for fully developed turbulent flow in smooth } \\
\text { tubes for fluid with Prandtl numbers ranging from } \\
\text { about } 0.6 \text { to } 100 \text { and with moderate temperature } \\
\text { difference between wall and fluid conditions. }\end{array}$ \\
\hline $\begin{array}{l}\text { Equation } \\
\text { (B.2) }\end{array}$ & $\begin{array}{l}\text { Mc Adams } \\
\quad(1942)\end{array}$ & $\begin{aligned} \mathrm{Nu}_{b}= & 0.0243 \mathrm{Re}_{b}^{0.8} \operatorname{Pr}_{b}^{0.4} \\
& {[5,7,13,15] }\end{aligned}$ & $\begin{array}{l}\text { Modified version of (B.1) used for supercritical } \\
\text { condition. }\end{array}$ \\
\hline $\begin{array}{l}\text { Equation } \\
\text { (B.3) }\end{array}$ & $\begin{array}{l}\text { Bringer and } \\
\text { Smith (1957) }\end{array}$ & $\begin{array}{c}\mathrm{Nu}_{x}=0.0266 \mathrm{Re}_{x}^{0.77} \operatorname{Pr}_{w}^{0.55} \\
{[5,7] .}\end{array}$ & $\begin{array}{l}\mathrm{Nu}_{x} \text { and } \mathrm{Re}_{x} \text { are evaluated at } t_{x} . \text { Temperature } t_{x} \text { is } \\
\text { defined as } t_{b} \text { if }\left(t_{\mathrm{pc}}-t_{b}\right) /\left(t_{w}-t_{b}\right)<0 \text {, as } t_{\mathrm{pc}} \text { if } 0 \leq \\
\left(t_{\mathrm{pc}}-t_{b}\right) /\left(t_{w}-t_{b}\right) \leq 1 \text {, and as } t_{w} \text { if }\left(t_{\mathrm{pc}}-t_{b}\right) /\left(t_{w}-t_{b}\right)>1 \\
\text { for supercritical water up to } p=34.5 \mathrm{MPa} \text {. }\end{array}$ \\
\hline $\begin{array}{l}\text { Equation } \\
\text { (B.4) }\end{array}$ & $\begin{array}{l}\text { Shitsman (1959, } \\
\text { 1974) }\end{array}$ & $\begin{aligned} \mathrm{Nu}_{b}= & 0.023 \mathrm{Re}_{b}^{0.8} \operatorname{Pr}_{\min }^{0.8} \\
& {[5,7,19] . }\end{aligned}$ & $\begin{array}{l}\text { "min" means minimum Pr value, that is, either the Pr } \\
\text { value is evaluated at the bulk fluid temperature or the } \\
\text { Pr value is evaluated at the wall temperature, whichever } \\
\text { is less. Assumption: thermal conductivity is a smoothly } \\
\text { decreasing function of temperature near the critical and } \\
\text { pseudo-critical points. }\end{array}$ \\
\hline $\begin{array}{l}\text { Equation } \\
\text { (B.5) }\end{array}$ & $\begin{array}{l}\text { Bishop et al. } \\
\quad(1964)\end{array}$ & $\begin{array}{l}\mathrm{Nu}_{b}=0.0069 \operatorname{Re}_{b}^{0.9}(\operatorname{Pr})_{\mathrm{av}}^{0.66} \\
\left(\rho_{w} / \rho_{b}\right)^{0.43}(1+2.4(D / x)) \\
\quad[5,7,8,11,13,15]\end{array}$ & $\begin{array}{l}x \text { is the axial location along the heated length. } \\
\text { Pressure }=22.8-27.6 \mathrm{MPa} \text {, and bulk fluid temperature }= \\
282-527^{\circ} \mathrm{C} \text {. } \\
\text { Mass flux }=651-3662 \mathrm{~kg} / \mathrm{m}^{2} \mathrm{~s} \text {, and heat flux }= \\
0.31-3.46 \mathrm{MW} / \mathrm{m}^{2} .\end{array}$ \\
\hline $\begin{array}{l}\text { Equation } \\
\text { (B.6) }\end{array}$ & $\begin{array}{l}\text { Swenson et al. } \\
{[1]}\end{array}$ & $\begin{array}{c}\mathrm{Nu}_{w}=0.00459 \operatorname{Re}_{w}^{0.923}\left(\operatorname{Pr}_{w}\right)_{\mathrm{av}}^{0.613} \\
\left(\rho_{w} / \rho_{b}\right)^{0.231} \\
\mathrm{hD} / k_{w}=0.00459\left(\mathrm{GD} / \mu_{w}\right)^{0.923} \\
{\left[\left(\left(H_{w}-H_{b}\right)\left(\mu_{w}\right)\right) /\left(\left(T_{w}-T_{b}\right)\left(k_{w}\right)\right)\right]^{0.613}} \\
\left(\rho_{w} / \rho_{b}\right)^{0.231}[1,5-8,10,15,21] .\end{array}$ & $\begin{array}{l}\text { Pressure }=22.8-41.4 \mathrm{MPa} \text {, and bulk fluid temperature }= \\
75-576^{\circ} \mathrm{C} . \\
\text { Mass flux }=542-2150 \mathrm{~kg} / \mathrm{m}^{2} \mathrm{~s} . \\
\text { Assumption: thermal conductivity is a smoothly } \\
\text { decreasing function of temperature near the critical and } \\
\text { pseudo-critical points. }\end{array}$ \\
\hline $\begin{array}{l}\text { Equation } \\
\text { (B.7) }\end{array}$ & $\begin{array}{l}\text { Krasnoshchekov } \\
\text { et al. (1967) }\end{array}$ & $\begin{array}{l}\mathrm{Nu}=\mathrm{Nu}_{0}\left(\rho_{w} / \rho_{b}\right)^{0.3}\left[(\mathrm{Cp})_{\mathrm{av}} / \mathrm{Cp}_{b}\right]^{n}, \\
\text { where, according to Petukhov and } \\
\text { Kirillov }(1958), \mathrm{Nu}_{0}=\left[(\xi / 8) \mathrm{Re}_{b}\right. \\
\left.(\mathrm{Pr})_{\mathrm{av}}\right] /[12.7 \mathrm{Sqrt}(\xi / 8) \\
\left.\left((\mathrm{Pr})_{\mathrm{av}}^{(2 / 3)}-1\right)+1.07\right] \text { and } \xi=1 /(1.82 \\
\left.\log _{10} \operatorname{Re}_{b}-1.64\right)^{2} \text {. } \\
\text { Later, Krasnoshchekov et al. (1971) added } \\
\text { a correction factor to the above equation } \\
\text { for the tube entrance region in the form } \\
\text { of } f(x / D)=0.95+0.95(x / D)^{0.8} \text {. } \\
\text { Also, this correction factor can be used } \\
\text { for a heated tube abrupt inlet within } \\
\quad 2 \leq x / D \leq 15[10] .\end{array}$ & $\begin{array}{l}\text { Exponent } n=0.4 \text { at } T_{w} / T_{\mathrm{pc}} \leq 1 \text { or } T_{b} / T_{\mathrm{pc}}>1.2 \leq 1, \\
n=n_{1}=0.22+0.18 T_{w} / T_{\mathrm{pc}} \text { at } 1 \leq T_{w} / T_{\mathrm{pc}} \leq 2.5 \text {, and } \\
n=n_{1}+\left(5 \cdot n_{1}-2\right) \times\left(1-T_{b} / T_{\mathrm{pc}}\right) \text { at } 1 \leq T_{b} / T_{\mathrm{pc}} \leq 1.2 . \\
\text { Valid within the following range: } \\
8 \times 10^{4}<\mathrm{Re}_{b}<5 \times 10^{5}, 0.85<\left(\mathrm{Pr}_{b}\right)_{\mathrm{av}}<65, \\
0.90<\left(\rho_{w} / \rho_{b}\right)<1.0,0.02<(\mathrm{Cp})_{\mathrm{av}} / \mathrm{Cp}_{b}<4.0, \\
0.9<T_{w} / T_{\mathrm{pc}}<2.5,4.6 \times 10^{4}<q<2.6 \times 10^{6} \text {, where } q \text { is } \\
\text { in } \mathrm{W} / \mathrm{m}^{2} \text { and } x / D \geq 15[5-8] .\end{array}$ \\
\hline $\begin{array}{l}\text { Equation } \\
\text { (B.8) }\end{array}$ & Kondrat'ev [20] & $\begin{array}{c}\mathrm{Nu}_{b}=0.020 \mathrm{Re}_{b}^{0.8} \\
{[5,7,20] .}\end{array}$ & $\begin{array}{l}\text { Valid within the range of } 10^{4}<\mathrm{Re}<4 \times 10^{5} \text { and } \\
t_{b}=130-600^{\circ} \mathrm{C} \text {. } \\
\text { This equation is not valid within the pseudo-critical } \\
\text { region. }\end{array}$ \\
\hline $\begin{array}{l}\text { Equation } \\
\text { (B.9) }\end{array}$ & $\begin{array}{l}\text { Ornatsky et al. } \\
\text { (1970) }\end{array}$ & $\mathrm{Nu}_{b}=0.023 \operatorname{Re}_{b}^{0.8} \operatorname{Pr}_{\min }^{0.8}\left(\rho_{w} / \rho_{b}\right)^{0.3}[5,7]$ & $\operatorname{Pr}_{\min }$ is in the minimum value of $\operatorname{Pr}_{w}$ or $\operatorname{Pr}_{b}$ \\
\hline $\begin{array}{l}\text { Equation } \\
\text { (B.10) }\end{array}$ & $\begin{array}{c}\text { Yamagata et al. } \\
{[3]}\end{array}$ & $\begin{array}{c}\mathrm{Nu}_{b}=0.0135 \operatorname{Re}_{b}^{0.85} \operatorname{Pr}_{b}^{0.8} F_{c} \\
{[3,5,7,8]}\end{array}$ & $\begin{array}{l}F_{c}=1 \text { for } E>1, F_{c}=0.67 \mathrm{Pr}_{\mathrm{pc}}^{-0.05}\left((\mathrm{Cp})_{\mathrm{av}} / \mathrm{Cp}_{b}\right)^{n 1} \text { for } \\
0 \leq E \leq 1, \\
F_{c}=\left((\mathrm{Cp})_{\mathrm{av}} / \mathrm{Cp}_{b}\right)^{n 2} \text { for } E<0, \\
E=\left(T_{\mathrm{pc}}-T_{b}\right) /\left(T_{w}-T_{b}\right) \\
n 1=-0.77\left(1+\left(1 / \mathrm{Pr}_{\mathrm{pc}}\right)\right)+1.49, \\
n 2=-1.44\left(1+\left(1 / \mathrm{Pr}_{\mathrm{pc}}\right)\right)-0.53 . \\
\text { Pressure }=226-294 \mathrm{bar} \text {, and bulk fluid temperature }= \\
230-540^{\circ} \mathrm{C} . \\
\text { Mass flux }=310-1830 \mathrm{~kg} / \mathrm{m}^{2} \mathrm{~s} \text {, heat flux }= \\
116-930 \mathrm{~kW} / \mathrm{m}^{2} .\end{array}$ \\
\hline
\end{tabular}


TABle 1: Continued.

\begin{tabular}{|c|c|c|c|}
\hline $\begin{array}{l}\text { Equation } \\
\text { no. }\end{array}$ & $\begin{array}{l}\text { Name of } \\
\text { correlation }\end{array}$ & Correlation & Conditions \\
\hline $\begin{array}{l}\text { Equation } \\
\text { (B.11) }\end{array}$ & $\begin{array}{l}\text { Watts and Chou } \\
\text { et al. (1982) }\end{array}$ & 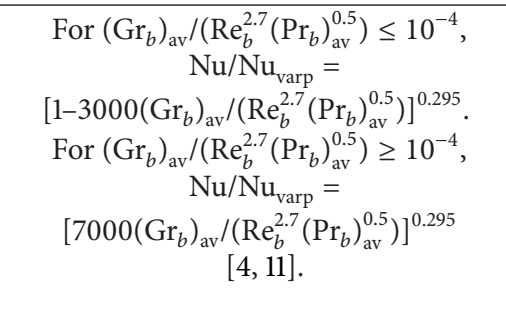 & $\begin{array}{l}\mathrm{Nu}=\alpha \mathrm{D} / \lambda_{b} \\
\mathrm{Nu}_{\mathrm{varp}}=0.021 \mathrm{Re}_{b}^{0.8}\left(\operatorname{Pr}_{b}\right)_{\mathrm{av}}^{0.55}\left(\rho_{w} / \rho_{b}\right)^{0.35}, \\
\left(\mathrm{Gr}_{b}\right)_{\mathrm{av}}=\left[\rho_{b}\left(\rho_{b}-\rho_{\mathrm{av}}\right) \mathrm{gD}^{3}\right] / \mu_{b}^{2}, \\
\mathrm{Re}_{b}=\mathrm{GD} / \mu, \\
\left(\mathrm{Pr}_{b}\right)_{\mathrm{av}}=\mathrm{Cp}_{\mathrm{av}} \mu_{b} / \lambda_{b}, \\
\mathrm{Cp}_{\mathrm{av}}=\left(H_{w}-H_{b}\right) /\left(T_{w}-T_{b}\right) . \\
\rho_{\mathrm{av}}=[\text { Integral }(\rho \mathrm{dT})] \text { with limits } T_{w} \text { and } T_{b} /\left[T_{w}-T_{b}\right]\end{array}$ \\
\hline $\begin{array}{l}\text { Equation } \\
\text { (B.12) }\end{array}$ & $\begin{array}{l}\text { Gorban et al. } \\
\quad(1990)\end{array}$ & $\begin{array}{c}\mathrm{Nu}_{b}=0.0059 \mathrm{Re}_{b}^{0.90} \operatorname{Pr}_{b}^{-0.12} \\
{[5,7]}\end{array}$ & \\
\hline $\begin{array}{l}\text { Equation } \\
\text { (B.13) }\end{array}$ & Griem (1996) & $\begin{array}{c}\mathrm{Nu}_{b}=0.0169 \mathrm{Re}_{b}^{0.8356} \operatorname{Pr}_{b}^{0.432} \\
{[5,7,8]}\end{array}$ & $\begin{array}{l}\text { It covers the entire enthalpy range due to a new method } \\
\text { for determining a representative specific heat capacity. } \\
\text { Heat capacities were computed with semiempirical } \\
\text { equations at five reference temperatures. }\end{array}$ \\
\hline $\begin{array}{l}\text { Equation } \\
\text { (B.14) }\end{array}$ & $\begin{array}{l}\text { Kitoh et al. } \\
\text { (1999) }\end{array}$ & $\begin{aligned} \mathrm{Nu}_{b}= & 0.015 \mathrm{Re}_{b}^{0.85} \operatorname{Pr}_{b}^{m} \\
& {[5,7,10] . }\end{aligned}$ & $\begin{array}{l}m=0.69-81000 / q_{\mathrm{dht}}+f_{c} q \text {. } \\
\text { The heat flux }\left(q_{\mathrm{dht}}\right) \text { is that at which deterioration-rated } \\
\text { heat transfer occurs }\left(\mathrm{W} / \mathrm{m}^{2}\right) \text {. } \\
\text { The heat flux is calculated according to } q_{\mathrm{dth}}=200 \mathrm{G}^{1.2} \text {. } \\
\text { The coefficient } f_{c} \text { is calculated according to } \\
f_{c}=29 \times 10^{-8}+0.11 / q_{\mathrm{dht}} \text { for } 0 \leq H_{b} \leq 1500 \mathrm{~kJ} / \mathrm{kg} \text {, } \\
f_{c}=-8.7 \times 10^{-8}-0.65 / q_{\mathrm{dht}} \text { for } 1500 \leq H_{b} \leq 3300 \mathrm{~kJ} / \mathrm{kg} \text {, } \\
f_{c}=-9.7 \times 10^{-7}-1.30 / q_{\mathrm{dht}} \text { for } 3300 \leq H_{b} \leq 4000 \mathrm{~kJ} / \mathrm{kg} \text {. } \\
\text { Valid for } T_{b} \text { from } 20^{\circ} \mathrm{C} \text { to } 550^{\circ} \mathrm{C} \text { (bulk fluid enthalpy } \\
\text { from } 100 \text { to } 3300 \mathrm{~kJ} / \mathrm{kg}), G \text { from } 100 \text { to } 1750 \mathrm{~kg} / \mathrm{m}^{2} \mathrm{~s} \text {, and } \\
q \text { from } 0 \text { to } 1.8 \mathrm{MW} / \mathrm{m}^{2} \text {. }\end{array}$ \\
\hline $\begin{array}{l}\text { Equation } \\
\text { (B.15) }\end{array}$ & Jackson (2002) & $\begin{array}{c}\mathrm{Nu}_{b}=0.0183 \operatorname{Re}_{b}^{0.82}\left(\operatorname{Pr}_{b}\right)_{\mathrm{av}}^{0.5}\left(\rho_{w} / \rho_{b}\right)^{0.3} \\
\left.\left[(\mathrm{Cp})_{\mathrm{avv}} / \mathrm{Cp}_{b}\right)\right]^{n} \\
{[5-7,11,15]}\end{array}$ & $\begin{array}{l}\text { Exponent } \\
n=0.4 \text { for } T_{b}<T_{w}<T_{\mathrm{pc}} \text { and for } 1.2 T_{\mathrm{pc}}<T_{b}<T_{w} \\
n=0.4+0.2\left(\left(T_{w} / T_{\mathrm{pc}}\right)-1\right) \text { for } T_{b}<T_{\mathrm{pc}}<T_{w} \\
n=0.4+0.2\left(\left(T_{w} / T_{\mathrm{pc}}\right)-1\right)\left[1-5\left(\left(T_{b} / T_{\mathrm{pc}}\right)-1\right) \text { for }\right. \\
T_{\mathrm{pc}}<T_{b}<1.2 T_{\mathrm{pc}}, \text { and } T_{b}<T_{w} . \\
T_{b}, T_{\mathrm{pc}}, \text { and } T_{w} \text { are in } K \text {. } \\
\text { Valid for forced convection heat transfer in water and } \\
\text { carbon dioxide at supercritical pressures. }\end{array}$ \\
\hline $\begin{array}{l}\text { Equation } \\
\text { (B.16) }\end{array}$ & $\begin{array}{l}\text { Kang and Chang } \\
\text { et al. [11] }\end{array}$ & $\begin{array}{c}\mathrm{Nu}_{b}=0.0244 \operatorname{Re}_{b}^{0.762} \operatorname{Pr}_{\mathrm{av}}^{0.552}\left(\rho_{w} / \rho_{b}\right)^{0.0293} \\
{[11] .}\end{array}$ & $\begin{array}{l}\text { Fluidfreon, HFC134a. } \\
\text { Pressure: } 4.1 \text { to } 4.5 \mathrm{MPa} \text {, mass flux: } 600 \text { to } 2000 \mathrm{~kg} / \mathrm{m}^{2} \mathrm{~s} \text {, } \\
\text { and heat flux: up to } 160 \mathrm{~kW} / \mathrm{m}^{2} \text {. }\end{array}$ \\
\hline $\begin{array}{l}\text { Equation } \\
\text { (B.17) }\end{array}$ & Zhu et al. [12] & $\begin{array}{l}\mathrm{Nu}_{b}=0.0068 \operatorname{Re}_{b}^{0.90}\left(\operatorname{Pr}_{b}\right)_{\mathrm{av}}^{0.63} \\
\quad\left(\rho_{w} / \rho_{b}\right)^{0.17}\left(k_{w} / k_{b}\right)^{0.29}[12]\end{array}$ & $\begin{array}{l}\text { Pressure: } 90-300 \mathrm{bar} \text {, mass flux: } 600-1200 \mathrm{~kg} / \mathrm{m}^{2} \mathrm{~s} \text {, and } \\
\text { heat flux: } 200-600 \mathrm{~kW} / \mathrm{m}^{2} .\end{array}$ \\
\hline $\begin{array}{l}\text { Equation } \\
\text { (B.18) }\end{array}$ & Mokry et al. [15] & $\begin{array}{c}\mathrm{Nu}_{b}=0.0061 \mathrm{Re}_{b}^{0.904}\left(\operatorname{Pr}_{b}\right)_{\mathrm{av}}^{0.684} \\
\left(\rho_{w} / \rho_{b}\right)^{0.564} \\
{[15]}\end{array}$ & $\begin{array}{l}\text { Pressure: } 24 \mathrm{MPa} \text {, inlet fluid temperature: } 320-350^{\circ} \mathrm{C} \text {, } \\
\text { mass flux: } 200-1500 \mathrm{~kg} / \mathrm{m}^{2} \mathrm{~s} \text {, and heat flux } \leq \\
1250 \mathrm{~kW} / \mathrm{m}^{2} \text {. }\end{array}$ \\
\hline
\end{tabular}

each point in the graph were calculated with experimental wall temperature as base. The correlations were ranked based on criteria like $\%$ predictions with $<5 \%$ error, $\%$ predictions with $<10^{\circ} \mathrm{C}$ error, and minimum deviation in temperature prediction for the selected dataset. The trend of wall temperature predicted by the best fitting correlation was plotted along with experimental temperature. Details of the best fitting correlation were tabulated. The observations are given below.

4.1. Experiments of Vikhrev et al. (1967) [7, 18]. Figures 2 and 3 display the trends of inner wall temperatures calculated by the best fitting correlations along with reference experimental wall temperatures for two different operating conditions given in $[7,18]$. Table 2 details the parameter conditions and the comparative information on the predicted wall temperature of the best fitting correlation with reference to the experimental wall temperature.

The experimental wall temperature trend seen in Figure 2 indicates heat-transfer deteriorations at two locations: one near the entry and the other near the exit at locations where the fluid temperatures are well below the pseudocritical temperature. No deterioration phenomenon is predicted even by the best fitting correlation. Similarly, the smooth drop in wall temperature occurring well before pseudocritical temperature and the sudden peaking of wall temperature at a fluid temperature of $387.6^{\circ} \mathrm{C}$ just before pseudocritical 


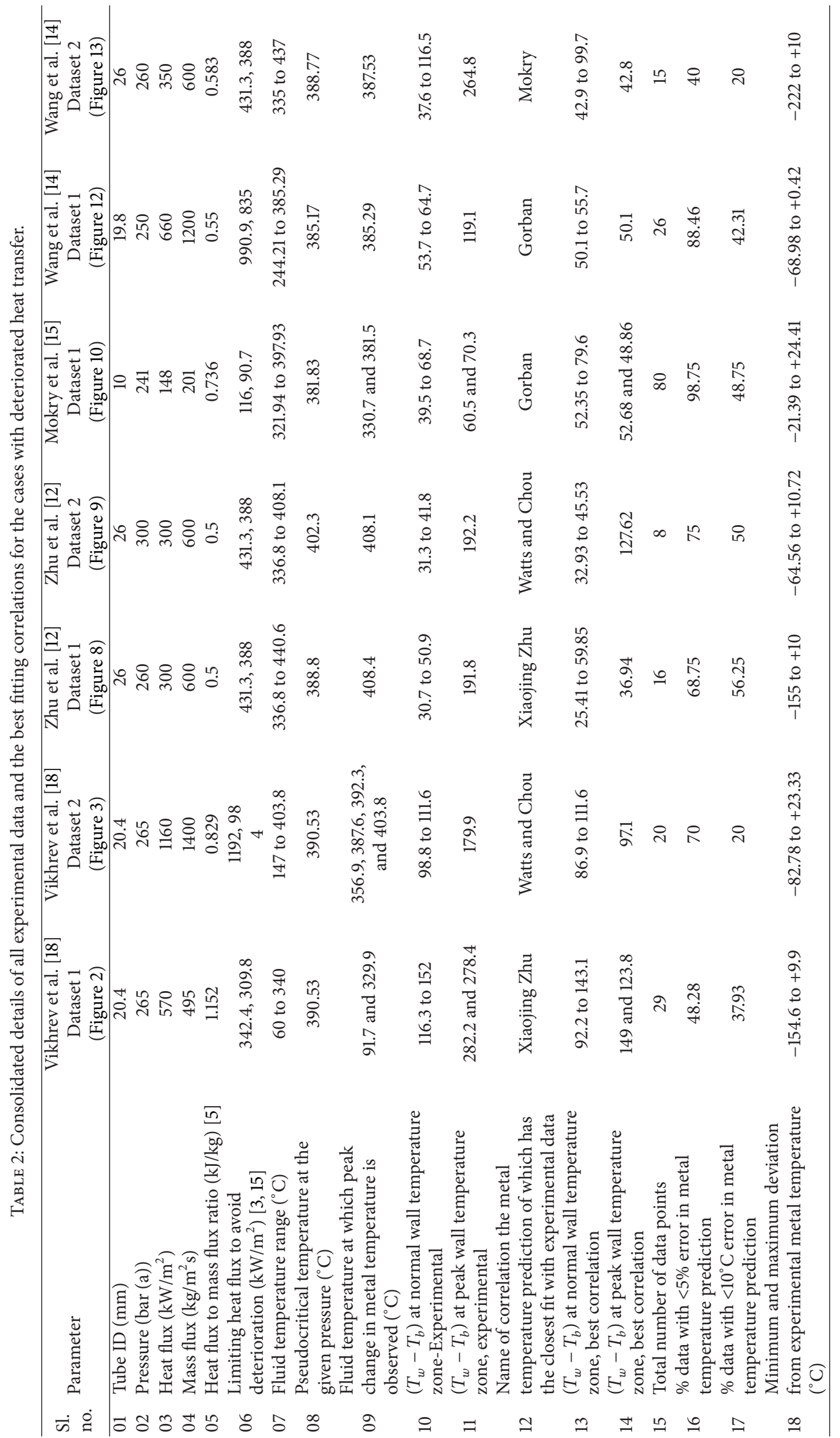




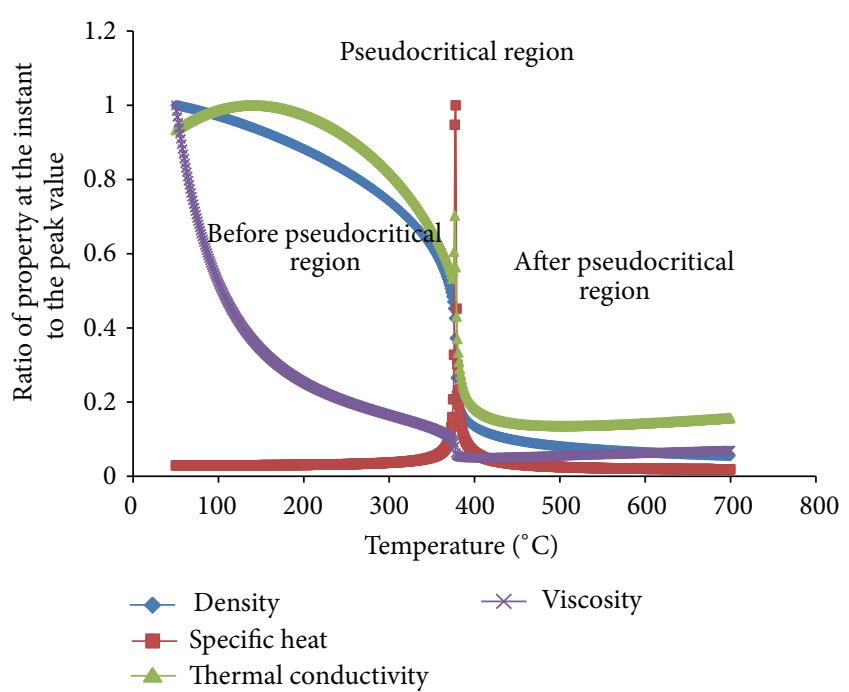

FIgURE 1: Trends of the thermophysical properties of water at 230 bar.

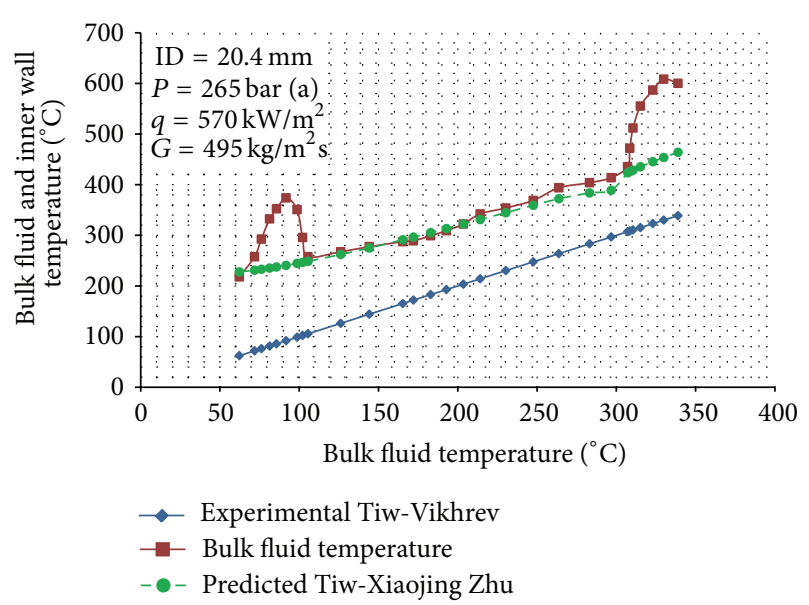

FIgure 2: Trends of experimental (Vikhrev et al. [18]) wall temperature and that calculated using the best fitting Xiaojing Zhu correlation for dataset 1 in Table 2.

temperature seen in Figure 3 are not predicted even by the best fitting correlation.

4.2. Experiments of Yamagata et al. (1972) [3]. Figures 4 and 5 display the trends of inner wall temperatures calculated by the best fitting correlations along with reference experimental wall temperatures for two different operating conditions given in [3]. Table 3 details the parameter conditions and the comparative information on the predicted wall temperature of the best fitting correlation with reference to the experimental wall temperature.

Observations of Figure 4 and Table 3 for dataset 1 indicate very good agreement of the best fitting correlation even at pseudocritical temperature. Also, many correlations predict $100 \%$ agreement for the first two considerations of $\%$ data with $<5 \%$ error and $<10^{\circ} \mathrm{C}$ error in prediction. Though there is $100 \%$ agreement for the best fitting correlation as per

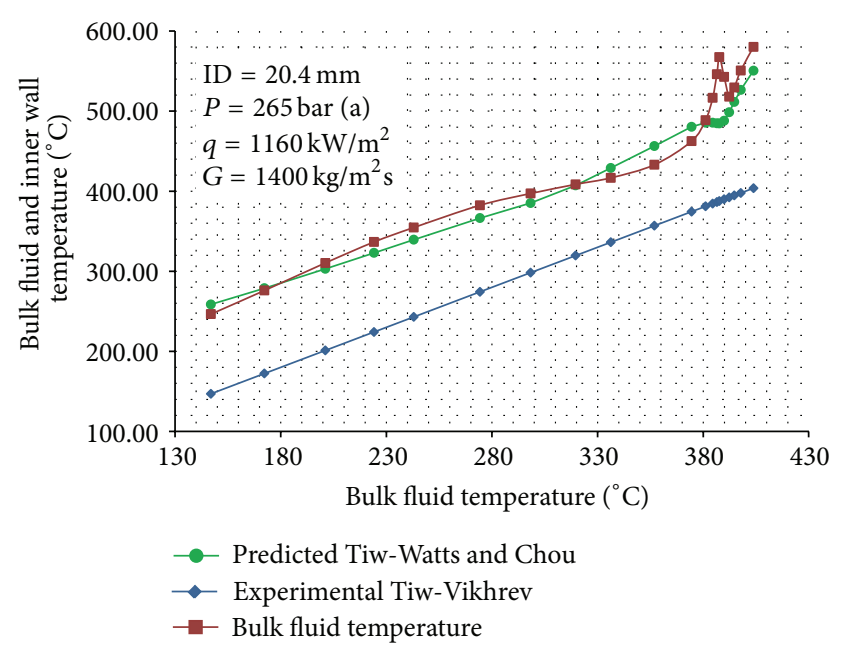

Figure 3: Trends of experimental (Vikhrev et al. [18]) wall temperature and that calculated using the best fitting Watts and Chou correlation for dataset 2 in Table 2 .

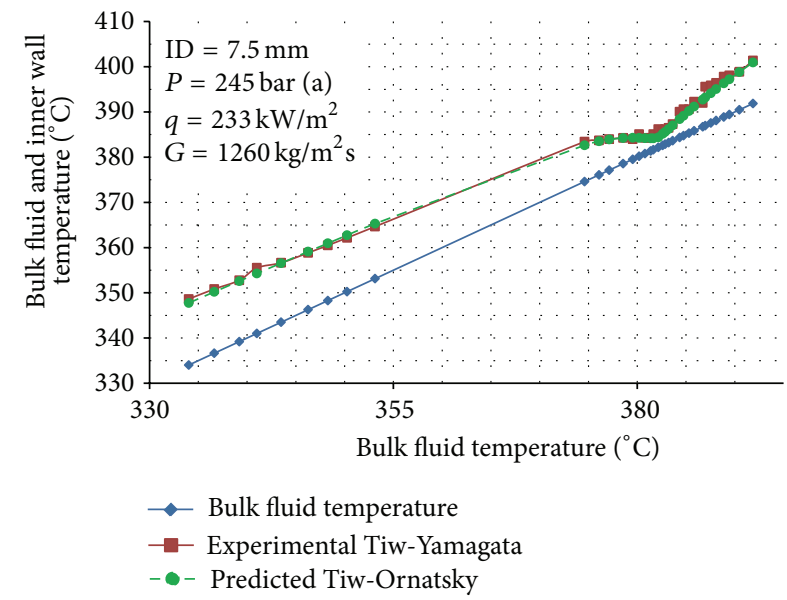

Figure 4: Trends of experimental (Yamagata et al. [3]) wall temperature and that calculated using the best fitting Ornatsky correlation for dataset 1 in Table 3 .

the selected criteria for dataset 2 , the wall temperature deviation is comparatively larger as seen in Figure 5.

4.3. Lookup Table Data of Loewenberg et al. (2008) [10]. Figures 6 and 7 display the trends of inner wall temperatures calculated by the best fitting correlations along with reference wall temperatures for two different operating conditions given in [10]. Table 3 details the parameter conditions and the comparative information on the predicted wall temperature of the best fitting correlation with reference to the experimental wall temperature.

Observation of Figure 6 and Table 3 for dataset 1 indicates very good agreement of the best fitting correlation even at pseudocritical temperature. Also, for this dataset, many correlations predict $100 \%$ agreement for the first two considerations of $\%$ data with $<5 \%$ error and $<10^{\circ} \mathrm{C}$ error in prediction. The observations of Figure 7 for dataset 2 indicate 


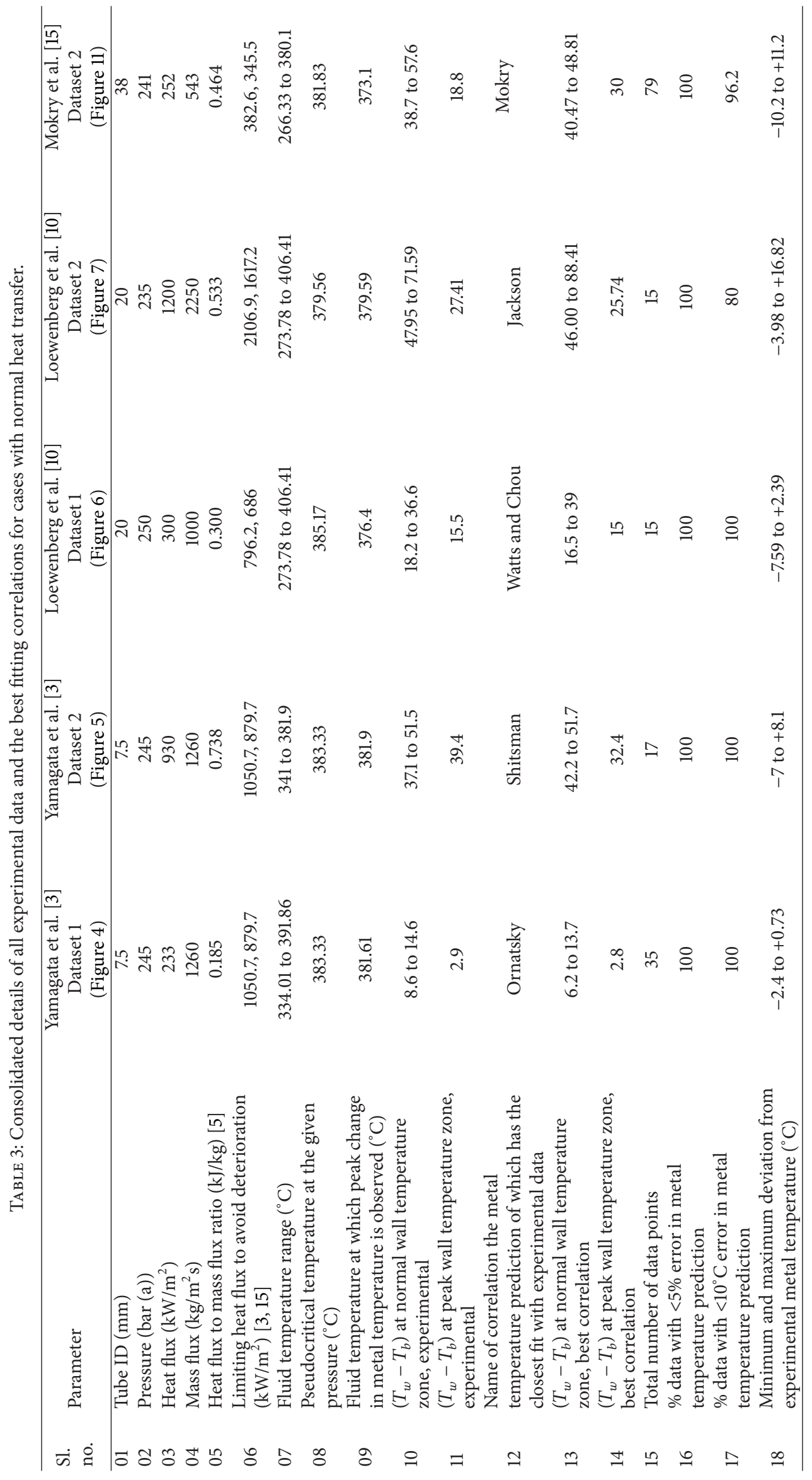




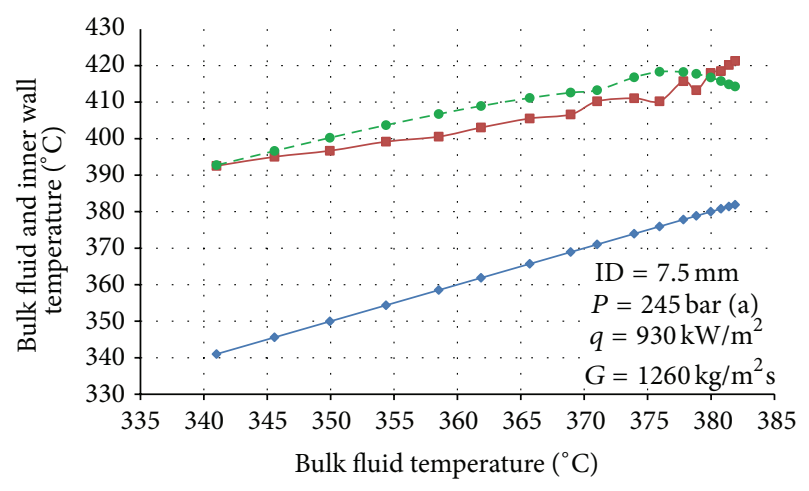

$\rightarrow$ Experimental Tiw-Yamagata
- Bulk fluid temperature
- - Predicted Tiw-Shitsman

FIGURE 5: Trends of experimental (Yamagata et al. [3]) wall temperature and that calculated using the best fitting Shitsman correlation for dataset 2 in Table 3.

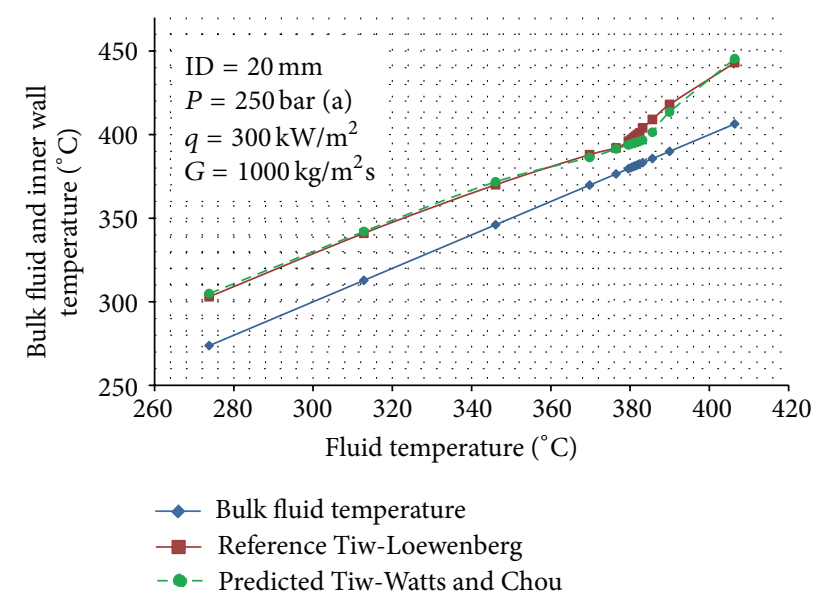

FIGURE 6: Trends of the lookup table (Loewenberg et al. [10]) wall temperature and that calculated using the best fitting Watts and Chou correlation for dataset 1 in Table 3 .

comparatively higher deviation in wall temperature and lower $\%$ agreement for the selected criteria even for the best fitting correlation.

4.4. Experiments of Zhu et al. (2009) [12]. Figures 8 and 9 display the trends of inner wall temperatures calculated by the best fitting correlations along with experimental wall temperatures for two different operating conditions given in [12]. Table 2 details the parameter conditions and the comparative information on the predicted wall temperature of the best fitting correlation with reference to the experimental wall temperature.

As per Figure 8 and dataset 1 in Table 2, the experimental wall temperature indicates a sharp peak of $600.2^{\circ} \mathrm{C}$ at a fluid temperature of $408.4^{\circ} \mathrm{C}$ with $\left(T_{w}-T_{b}\right)$ of $191.8^{\circ} \mathrm{C}$. None of the correlations indicate this peak. Even the best fitting correlation has only $68.5 \%$ of data with $<5 \%$ error

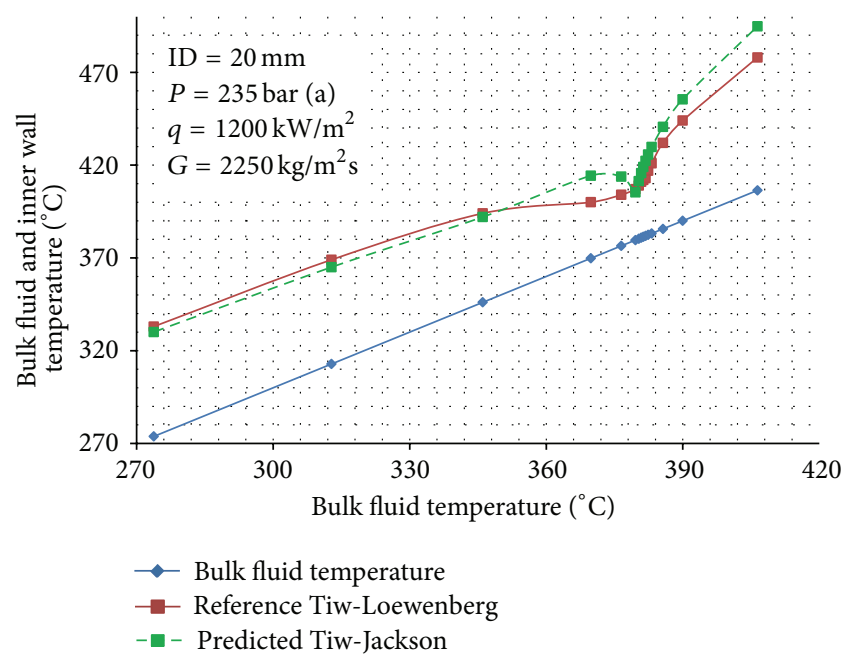

FIgURE 7: Trends of the lookup table (Loewenberg et al. [10]) wall temperature and that calculated using the best fitting Jackson correlation for dataset 2 in Table 3.

in prediction, and the error band for the overall data range is -155 to $+10^{\circ} \mathrm{C}$. Figure 9 and dataset 2 in Table 2 also indicate sharp increase in wall temperature near the exit. Though many correlations do not predict this peak, the best fitting correlation indicates this and follows the trend of experimental wall temperature. However, only $75 \%$ of data are with $<5 \%$ error in prediction, and the error band for the overall data range is -64.56 to $+10.72^{\circ} \mathrm{C}$.

4.5. Experiments of Mokry et al. (2011) [15]. Figures 10 and 11 display the trends of inner wall temperatures calculated by the best fitting correlations along with experimental wall temperatures for two different operating conditions given in [15]. Tables 2 and 3 detail the parameter conditions and the comparative information on the predicted wall temperature of the best fitting correlation with reference to the experimental wall temperature.

As per experimental dataset 1 in Table 2 and Figure 10, heat-transfer deterioration is observed at two locations: one near the entry where the fluid temperature is well below pseudocritical temperature and the other near exit at location where the fluid temperature is near the pseudocritical temperature. None of the correlations indicate the first peak, and all of them including the best correlation indicate a dip in wall temperature at the second location contrary to the experimental observation. Many correlations indicate parallel wall temperature trend for dataset 2 in Table 3. As seen in Figure 11, the best fitting correlation has minimum error band of -10.2 to $+11.2^{\circ} \mathrm{C}$ for the overall dataset.

4.6. Experiments of Wang et al. (2011) [14]. Figures 12 and 13 display the trends of inner wall temperatures calculated by the best fitting correlations along with experimental wall temperatures for two different operating conditions given in [14]. Table 2 details the parameter conditions and the comparative information on the predicted wall temperature of 


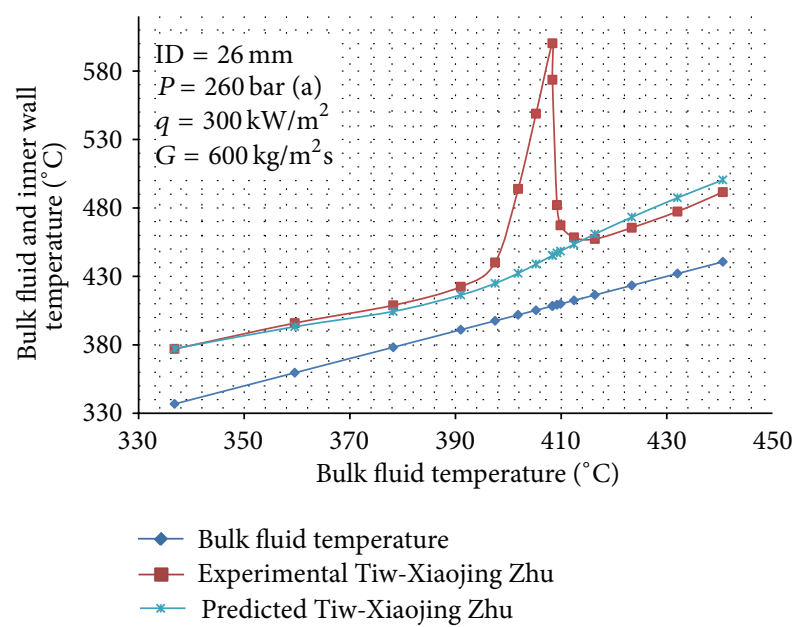

FIgURE 8: Trends of experimental (Zhu et al. [12]) wall temperature and that calculated using the best fitting Xiaojing Zhu correlation for dataset 1 in Table 2.

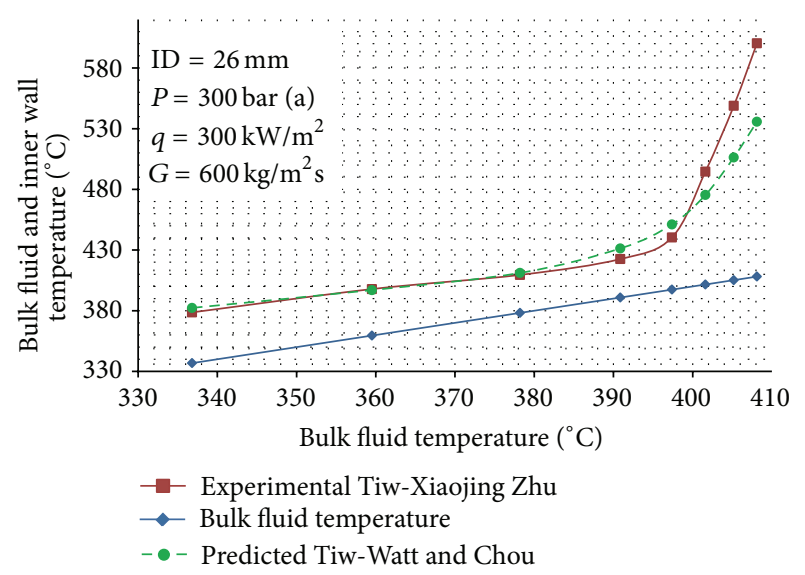

FIGURE 9: Trends of experimental (Zhu et al. [12]) wall temperature and that calculated using the best fitting Watts and Chou correlation for dataset 2 in Table 2.

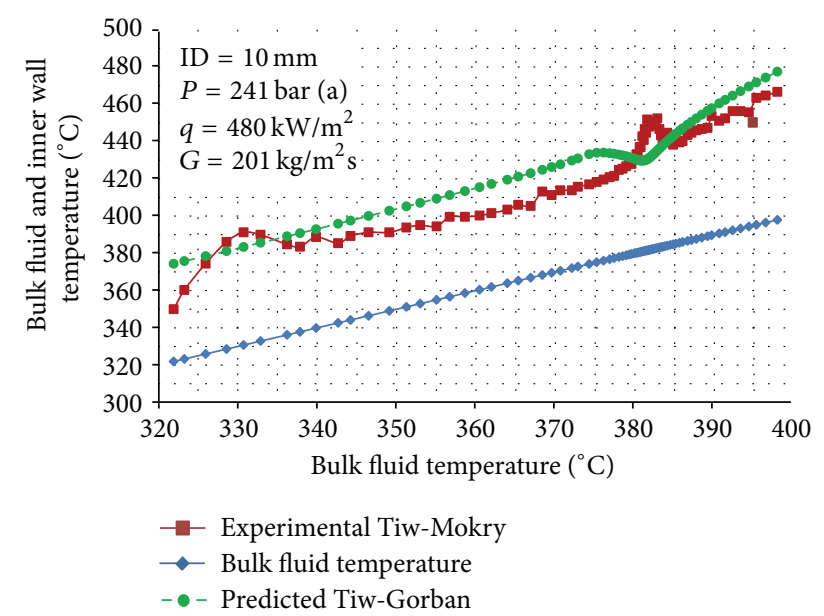

FIGURE 10: Trends of experimental (Mokry et al. [15]) wall temperature and that calculated using the best fitting Gorban correlation for dataset 1 in Table 2.

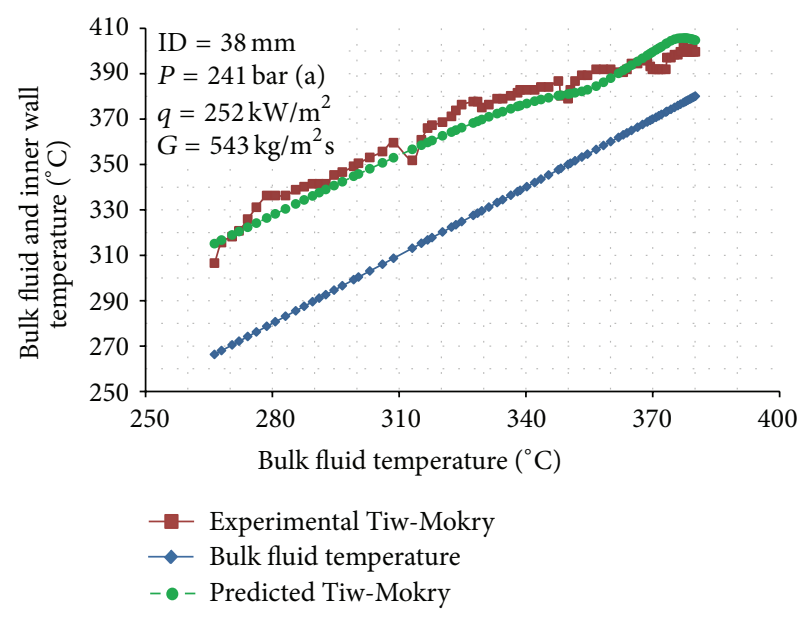

FIgure 11: Trends of experimental (Mokry et al. [15]) wall temperature and that calculated using the best fitting Sarah Mokry correlation for dataset 2 in Table 3.

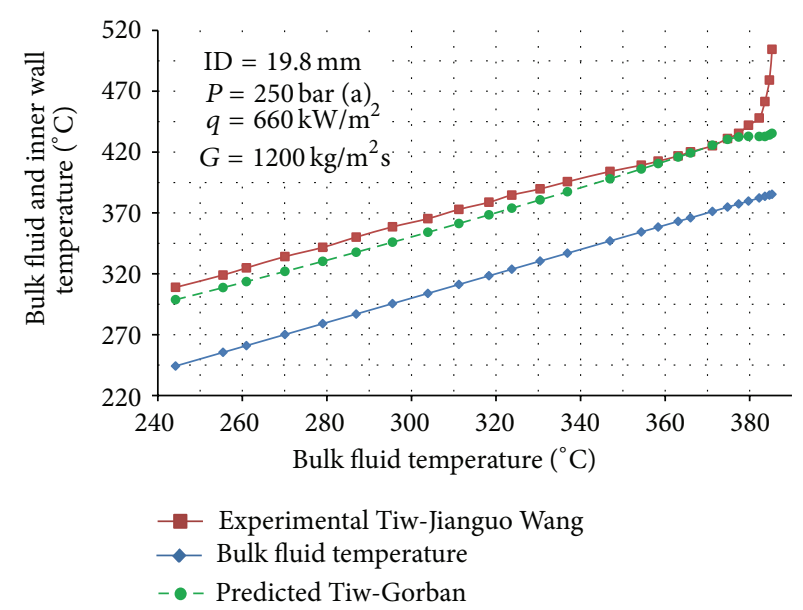

Figure 12: Trends of experimental (Wang et al. [14]) wall temperature and that calculated using the best fitting Gorban correlation for dataset 1 in Table 2.

the best fitting correlation with reference to the experimental wall temperature.

Dataset 1 in Table 2 and Figure 12 indicate sharp increase in wall temperature near the exit where the fluid temperature is just above pseudocritical temperature. None of the correlations, including the best one, indicate this peak, and all of them show a dip in temperature near the exit contradicting the experimental observation. The prediction by Gorban correlation has $88.46 \%$ of predictions with $<5 \%$ error with the error band of -68.98 to $+0.42^{\circ} \mathrm{C}$ for the overall dataset. As per Figure 13 and dataset 2 in Table 2, the experimental wall temperature indicates a sharp peak of $652.3^{\circ} \mathrm{C}$ at a fluid temperature of $387.53^{\circ} \mathrm{C}$ with $\left(T_{w}-T_{b}\right)$ of $264.8^{\circ} \mathrm{C}$. None of the correlations indicate this peak. Even the best fitting correlation has only $40 \%$ of the data with $<5 \%$ error in prediction, and the error band for the overall data range is -222 to $+10^{\circ} \mathrm{C}$. 


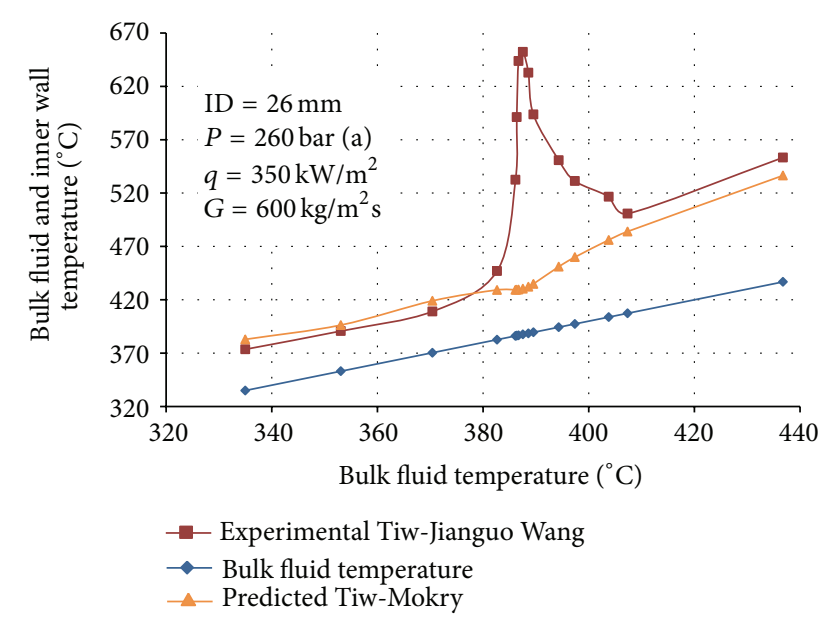

Figure 13: Trends of experimental (Wang et al. [14]) wall temperature and that calculated using the best fitting Sarah Mokry correlation for dataset 2 in Table 2.

The analysis of the above wall temperature figures and the values in the tables indicate that even the best fitting correlations agree well only in the normal heat-transfer zones and not in the deteriorated heat-transfer zones.

\section{Results and Discussion}

5.1. Wall Temperature Prediction Capability of Heat-Transfer Correlations. Analyses of the 12 experimental datasets indicate that there are 7 deteriorated and 5 normal heat-transfer conditions in the group. The consolidated information of the selected experimental works and the data on the prediction level of the best fitting correlation for each dataset are listed in Table 2 for the deteriorated and in Table 3 for the normal heat-transfer conditions. As seen in the tables, the Watts and Chou correlation is the best for 2 deteriorated and 1 normal heat-transfer cases, the Gorban and Xiaojing Zhu correlations are the best for each 2 deteriorated heat-transfer cases, the Mokry correlation is the best for 1 deteriorated and 1 normal heat-transfer cases, and the Ornatsky, Shitsman and Jackson correlations are the best for each 1 normal heat-transfer case.

It is observed that the agreement of the predictions of the best fitting correlations for 5 normal heat transfer cases indicates almost $100 \%$ of the prediction satisfying the $<5 \%$ and $<10^{\circ} \mathrm{C}$ error criteria with the maximum error band at -10.2 to $+16.82^{\circ} \mathrm{C}$. However, the agreement of the predictions of the best fitting correlations for 7 deteriorated heat-transfer cases shows lower $\%$ of the prediction satisfying the $<5 \%$ and $<10^{\circ} \mathrm{C}$ error criteria. Also, the error band is as high as -222 to $+24.41^{\circ} \mathrm{C}$. It is also observed that the best fitting correlation position keeps varying from case to case under the selected criteria. In few cases, many correlations have the same \% of agreement with respect to the $<5 \%$ and $<10^{\circ} \mathrm{C}$ error criteria, and the best is selected based on the difference in the error band.

Zahalan et al. [22, 23] conducted an extensive literature survey, analyzed the capability of 14 correlations for wall temperature prediction, and opined that the correlation by
Mokry et al. showed quite good predictions for subcritical liquid and superheated steam compared to other correlations. Based on the overall weighted average and root mean square (RMS) errors, Zahalan et al. [22, 23] determined that, within the supercritical region, the latest correlation by Mokry et al. showed the best for data within all three subregions investigated.

Similar analysis was made in the current work for all of the selected 355 data points. The details of average and RMS errors of metal temperature predictions for different correlations are listed in Table 4. As seen in the table, the Mokry et al. correlation was the best as per weighted average error. The weighted average error of the Krasnoschekov correlation is lesser than that of Mokry et al. However, it is not considered since it was only for 9 applicable data points out of the selected 355 data points. The Xiaojing Zhu correlation was the best as per RMS errors. Though the RMS errors of Krasnoschekov, Kondrat'ev, and Bishop correlations are lower than that of Xiaojing Zhu, they were not considered since they were applicable only for 9, 282, and 66 data points, respectively, out of the selected 355 datasets.

\subsection{Applicability of Heat Flux to Mass Flux Ratio for Predicting} Deteriorated Heat Transfer. Articles $[5,7,18]$ report that heattransfer deterioration occurs for operating conditions with the ratio of heat flux to mass flux $(q / G)$ greater than 0.4 . Analysis of the 12 experiments and the details in Tables 2 and 3 indicate that $q / G$ ratios for two experiments are less than 0.4 and the metal temperatures for these two cases are normal. For ten cases, the $q / G$ ratio is greater than 0.4 . Seven out of these ten exhibit deteriorated wall temperature conditions. Though the $q / G$ ratios for the remaining three (Table 3 ) are greater than 0.4 , the experimental wall temperatures are normal. The overall agreement of the $q / G$-ratio-based prediction is $75 \%$ for the 12 experiments selected in this paper.

\subsection{Applicability of the Empirical Formulae for Predicting} Limiting Heat Flux. Articles [7, 8] report (4), and article [3] reports (5) given below for predicting the starting heat flux for deteriorated heat transfer as a function of mass flux:

$$
q_{\mathrm{dht}} \text { in } \mathrm{W} / \mathrm{m}^{2}=200 G^{1.2}
$$

(see $[7,8])$,

$$
q_{\mathrm{dht}} \text { in } \mathrm{kW} / \mathrm{m}^{2}=0.2 G^{1.2}
$$

(see [3]).

Analysis of the 12 experiments and the details in Tables 2 and 3 indicate that there are two experiments in which the heat flux is higher than the heat flux calculated by (4) and (5) and the wall temperatures for these two cases indicate deterioration. Though the experimental heat flux is less than those calculated by (4) and (5), the experimental wall temperatures indicate deteriorated condition for five more cases. The overall agreement of the prediction of the deteriorated heat transfer by (4) and (5) is $58.33 \%$ for the 12 experiments selected in this paper. 
TABLE 4: Average and RMS errors of wall temperature prediction by various correlations for the selected data points.

\begin{tabular}{|c|c|c|c|c|}
\hline Equation no. & Correlation & Average error (\%) & RMS error (\%) & No. of applicable data points \\
\hline Equation (B.1) & Dittus and Boelter (1930) & -5.2500 & 9.4837 & All 355 \\
\hline Equation (B.2) & Mc Adams (1942) & -5.7839 & 9.8609 & All 355 \\
\hline Equation (B.3) & Bringer and Smith (1957) & -5.1090 & 9.6819 & All 355 \\
\hline Equation (B.4) & Shitsman $(1959,1974)$ & -3.7453 & 8.5276 & All 355 \\
\hline Equation (B.5) & Bishop et al. (1964) & -3.8194 & 6.5453 & 66 \\
\hline Equation (B.6) & Swenson et al. [1] & 6.5411 & 14.4906 & 90 \\
\hline Equation (B.7) & Krasnoshchekov et al. (1967) & 0.0237 & 0.1560 & 9 \\
\hline Equation (B.8) & Kondrat'ev [20] & -1.2354 & 6.4086 & 282 \\
\hline Equation (B.9) & Ornatsky et al. (1970) & -1.2940 & 8.9133 & All 355 \\
\hline Equation (B.10) & Yamagata et al. [3] & -7.0392 & 11.0684 & All 355 \\
\hline Equation (B.11) & Watts and Chou et al. (1982) & -3.6744 & 8.3295 & All 355 \\
\hline Equation (B.12) & Gorban et al. (1990) & -1.0198 & 7.9306 & 169 \\
\hline Equation (B.13) & Griem (1996) & -6.4152 & 10.2791 & All 355 \\
\hline Equation (B.14) & Kitoh et al. (1999) & -6.5683 & 10.5762 & 340 \\
\hline Equation (B.15) & Jackson (2002) & -4.4797 & 8.6144 & All 355 \\
\hline Equation (B.16) & Kang and Chang et al. [11] & -1.6150 & 7.8109 & All 355 \\
\hline Equation (B.17) & Zhu et al. [12] & -3.7481 & $7.7072^{*}$ & All 355 \\
\hline Equation (B.18) & Mokry et al. [15] & $-0.0489^{*}$ & 8.8816 & All 355 \\
\hline
\end{tabular}

${ }^{*}$ The lowest of the correlations applied to all 355 data points.

Article [15] reports (6) given below for predicting the starting heat flux for deteriorated heat transfer as a function of mass flux:

$$
q_{\mathrm{dht}} \text { in } \mathrm{kW} / \mathrm{m}^{2}=-58.97+0.745 G
$$

(see [15]).

For the same mass flux conditions, the starting heat flux for deteriorated heat transfer predicted by (6) is lower than that calculated by (4) and (5). Analysis of the 12 experiments and the details in Tables 2 and 3 indicate that there are four experiments in which the heat flux is higher than that calculated by (6). The wall temperatures for three of these four cases indicate deterioration, whereas no deterioration is observed for one case. Though the experimental heat flux is less than that calculated by (6), the experimental wall temperatures indicate deteriorated condition for four more cases. The overall agreement of the prediction of the deteriorated heat transfer by (6) is $58.33 \%$ for the 12 experiments selected in this paper.

\section{Conclusion}

The validity of the wall temperature predictions by 18 correlations for 12 supercritical experimental datasets consisting of 355 data points available in the literature was verified. The correlations were ranked based on criteria like \% data with $<5 \%$ error, $\%$ data with $<10^{\circ} \mathrm{C}$ error, and minimum error band in temperature prediction for the overall dataset. The trends of closely fitting predicted wall temperatures were plotted along with experimental wall temperature. Details of the best fitting correlations were tabulated.

The analysis indicated that, for normal heat-transfer conditions, most of the correlations give close predictions.
However, at deteriorated heat-transfer regimes near pseudocritical temperature, only very few predictions are closer with lower percentage of data falling close to experimental value. Also, in the ranking process, the first position keeps varying from case to case under the selected criteria. That is, no one correlation shall be said as the best for all experiments.

Analysis of the entire 355 datasets together, based on average and RMS errors, indicated that the Mokry et al. correlation was the best as per weighted average error and the Xiaojing Zhu correlation was the best as per RMS error for the selected experimental cases.

Evaluation of the applicability of heat flux to mass flux ratio- $(q / G-)$ based prediction of heat-transfer deterioration given in $[5,7,18]$ indicated $75 \%$ agreement for the selected 12 experimental cases. Evaluation of the empirical formulae linking mass flux for the prediction of the starting heat flux for heat-transfer deterioration given in $[3,7,8,15]$ indicated $58.33 \%$ of agreement for the selected 12 experimental cases.

This review indicated that continued precise experimentation covering wide range of parameter conditions near pseudocritical temperature regime and development of correlations is felt necessary for the accurate prediction of supercritical fluid heat transfer.

\section{Nomenclature}

C: Constant

Cp: Specific heat, $\mathrm{J} / \mathrm{kg} \mathrm{K}$

$\mathrm{Cp}_{\mathrm{av}}$ : Average specific heat $=\left(H_{w}-H_{b}\right) /\left(T_{w}-T_{b}\right)$ $\mathrm{J} / \mathrm{kg} \mathrm{K}$

$D: \quad$ Inner diameter of tube, $\mathrm{m}$

E: $\quad$ Ratio $\left(T_{\mathrm{pc}}-T_{b}\right) /\left(T_{w}-T_{b}\right)$

$F$ : Factor 
G: $\quad$ Mass flux, $\mathrm{kg} / \mathrm{m}^{2} \mathrm{~s}$

g: Acceleration due to gravity, $\mathrm{m} / \mathrm{s}^{2}$

$H$ : Enthalpy, J/kg

$h$ : Convection heat-transfer coefficient, $\mathrm{W} / \mathrm{m}^{2} \mathrm{~K}$

$k$ : Thermal conductivity, $\mathrm{W} / \mathrm{mK}$

L: $\quad$ Length, $\mathrm{m}$

p: $\quad$ Pressure, $\mathrm{MPa}$, bar

q: Heat flux, $\mathrm{kW} / \mathrm{m}^{2}$

$T, t$ : Temperature, ${ }^{\circ} \mathrm{C}$

$\mathrm{Nu}$ : Nusselt number

Re: Reynolds number

Pr: Prandtl number

$\mathrm{Pr}_{\mathrm{av}}$ : Average Prandtl number $=\mathrm{Cp}_{\mathrm{av}} \mu_{b} / k_{b}$.

\section{Greek Letters}

$\mu$ : Dynamic viscosity, Pa s

$\rho$ : Density, $\mathrm{kg} / \mathrm{m}^{3}$

$\xi$ : Friction coefficient

$\alpha$ : Heat-transfer coefficient

$\lambda$ : Thermal conductivity, $\mathrm{W} / \mathrm{mK}$.

\section{Subscript}

$\begin{array}{ll}\text { av: } & \text { Average } \\ b: & \text { Bulk } \\ \text { dht: } & \text { Deteriorated heat transfer } \\ w: & \text { Wall } \\ \text { iw: } & \text { Inner wall } \\ \text { pc: } & \text { Pseudocritical } \\ t: & \text { Temperature } \\ x: & \text { Axial location } \\ \text { hy: } & \text { Hydraulic } \\ \text { min: } & \text { Minimum. }\end{array}$

Superscript

$m$ : Constant

$n$ : Constant.

\section{References}

[1] H. S. Swenson, J. R. Carver, and C. R. Kakarala, "Heat transfer to supercritical water in smooth bore tubes," Journal of Heat Transfer, vol. 87, no. 4, pp. 477-484, 1965.

[2] A. W. Ackerman, "Pseudo boiling heat transfer to supercritical pressure water in smooth and ribbed tubes," Transactions of the ASME, vol. 92, pp. 490-497, 1970.

[3] K. Yamagata, K. Nishikawa, S. Hasegawa, T. Fujii, and S. Yoshida, "Forced convective heat transfer to supercritical water flowing in tubes," International Journal of Heat and Mass Transfer, vol. 15, no. 12, pp. 2575-2593, 1972.

[4] T. Yamashita, S. Yoshida, H. Mori, S. Morooka, H. Komita, and K. Nishida, "Heat transfer study under supercritical pressure conditions," GENE4/ANP2003, Paper 1119, Kyoto, Japan, 2003.

[5] I. L. Pioro, H. F. Khartabil, and R. B. Duffey, "Heat transfer to supercritical fluids flowing in channels-empirical correlations (survey)," Nuclear Engineering and Design, vol. 230, no. 1-3, pp. 69-91, 2004.

[6] F. Yin, T.-K. Chen, and H.-X. Li, "An investigation on heat transfer to supercritical water in inclined upward smooth tubes," Heat Transfer Engineering, vol. 27, no. 9, pp. 44-52, 2006.

[7] I. L. Pioro and R. B. Duffey, Heat Transfer and Hydraulic Resistance at Supercritical Pressures in Power-Engineering Applications, ASME Press, 2006-2007.

[8] X. Cheng, B. Kuang, and Y. H. Yang, "Numerical analysis of heat transfer in supercritical water cooled flow channels," Nuclear Engineering and Design, vol. 237, no. 3, pp. 240-252, 2007.

[9] P.-X. Jiang, Y. Zhang, C.-R. Zhao, and R.-F. Shi, "Convection heat transfer of $\mathrm{CO}_{2}$ at supercritical pressures in a vertical mini tube at relatively low reynolds numbers," Experimental Thermal and Fluid Science, vol. 32, no. 8, pp. 1628-1637, 2008.

[10] M. F. Loewenberg, E. Laurien, A. Class, and T. Schulenberg, "Supercritical water heat transfer in vertical tubes: a look-up table," Progress in Nuclear Energy, vol. 50, no. 2-6, pp. 532-538, 2008.

[11] K.-H. Kang and S.-H. Chang, "Experimental study on the heat transfer characteristics during the pressure transients under supercritical pressures," International Journal of Heat and Mass Transfer, vol. 52, no. 21-22, pp. 4946-4955, 2009.

[12] X. Zhu, Q. Bi, D. Yang, and T. Chen, "An investigation on heat transfer characteristics of different pressure steam-water in vertical upward tube," Nuclear Engineering and Design, vol. 239, no. 2, pp. 381-388, 2009.

[13] S. Mokry, I. Pioro, P. Kirillov, and Y. Gospodinov, "Supercriticalwater heat transfer in a vertical bare tube," Nuclear Engineering and Design, vol. 240, no. 3, pp. 568-576, 2010.

[14] J. Wang, H. Li, S. Yu, and T. Chen, "Comparison of the heat transfer characteristics of supercritical pressure water to that of subcritical pressure water in vertically-upward tubes," International Journal of Multiphase Flow, vol. 37, no. 7, pp. 769-776, 2011.

[15] S. Mokry, I. Pioro, A. Farah et al., "Development of supercritical water heat-transfer correlation for vertical bare tubes," Nuclear Engineering and Design, vol. 241, no. 4, pp. 1126-1136, 2011.

[16] S. B. Shiralkar and G. P. Griffith, "The effect of swirl, inlet conditions, flow direction, and tube diameter on the heat transfer to fluids at supercritical pressure," Journal of Heat Transfer, vol. 92, pp. 465-471, 1970.

[17] R. Dhanuskodi, A. Arunagiri, and N. Anantharaman, "Analysis of variation in properties and its impact on heat transfer in sub and supercritical conditions of water/steam," International Journal of Chemical Engineering and Applications, vol. 2, no. 5, pp. 320-325, 2011.

[18] Y. V. Vikhrev, Y. D. Barulin, and A. S. Kon'Kov, "A study of heat transfer in vertical tubes at supercritical pressures," Teploenergetika, vol. 14, no. 9, pp. 80-82, 1967.

[19] M. E. Shitsman, "Temperature conditions in tubes at supercritical pressures," Teploenergetika, vol. 15, no. 5, pp. 57-61, 1968.

[20] N. S. Kondratev, "Heat transfer and hydraulic resistance with supercritical water flowing in tubes," Teploeregetia, vol. 16, no. 8, pp. 49-51, 1969.

[21] M. Sharabi and W. Ambrosini, "Discussion of heat transfer phenomena in fluids at supercritical pressure with the aid of CFD models," Annals of Nuclear Energy, vol. 36, no. 1, pp. 60-71, 2009. 
[22] H. Zahalan, D. C. Groneveld, and S. Tavoularis, "Look-up table for trans-critical heat transfer," in Proceedings of the 2 nd Canada-China Joint Workshop on on Supercritical Water-Cooled Reactors (CCSC '10), p. 18, Toronto, Canada, April 2010.

[23] H. Zahalan, D. C. Groneveld, S. Tavoularis, S. Mokry, and I. Pioro, "Assessment of supercritical heat transfer prediction methods," in Proceedings of the 5th International Symposium on on Supercritical Water-Cooled Reactors (ISSWR '11), p. 20, British Columbia, Canada, March 2011, Paper P008. 


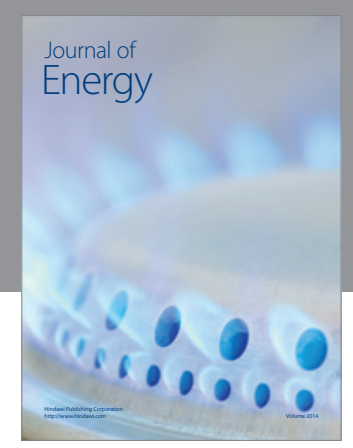

Journal of

Industrial Engineering
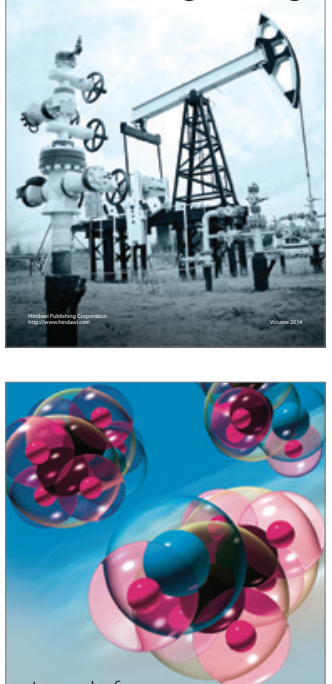

Fuels
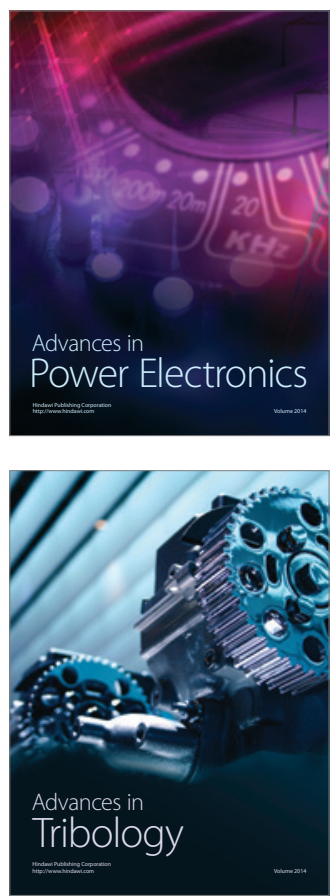

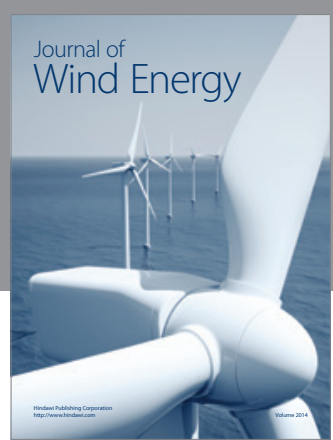

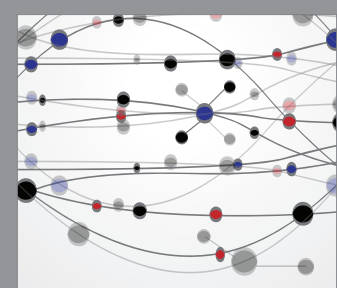

The Scientific World Journal

Submit your manuscripts at http://www.hindawi.com

Journal of

Structures
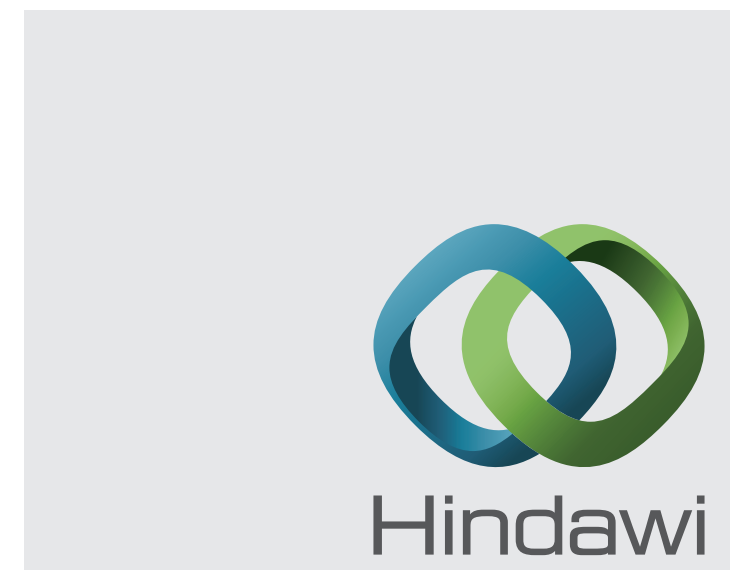

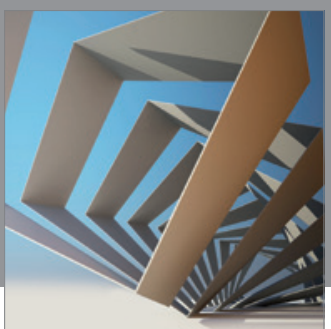

Rotating

Machinery
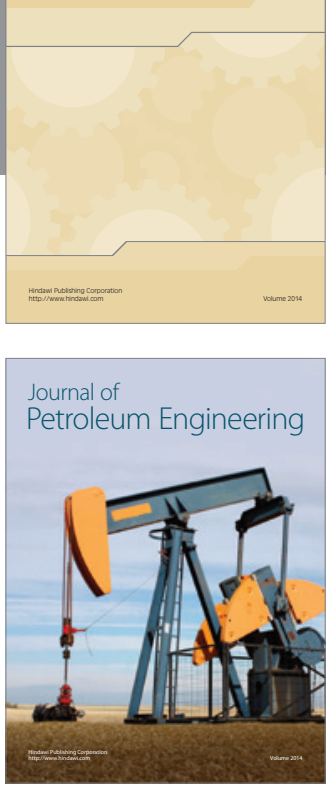

Journal of

Solar Energy
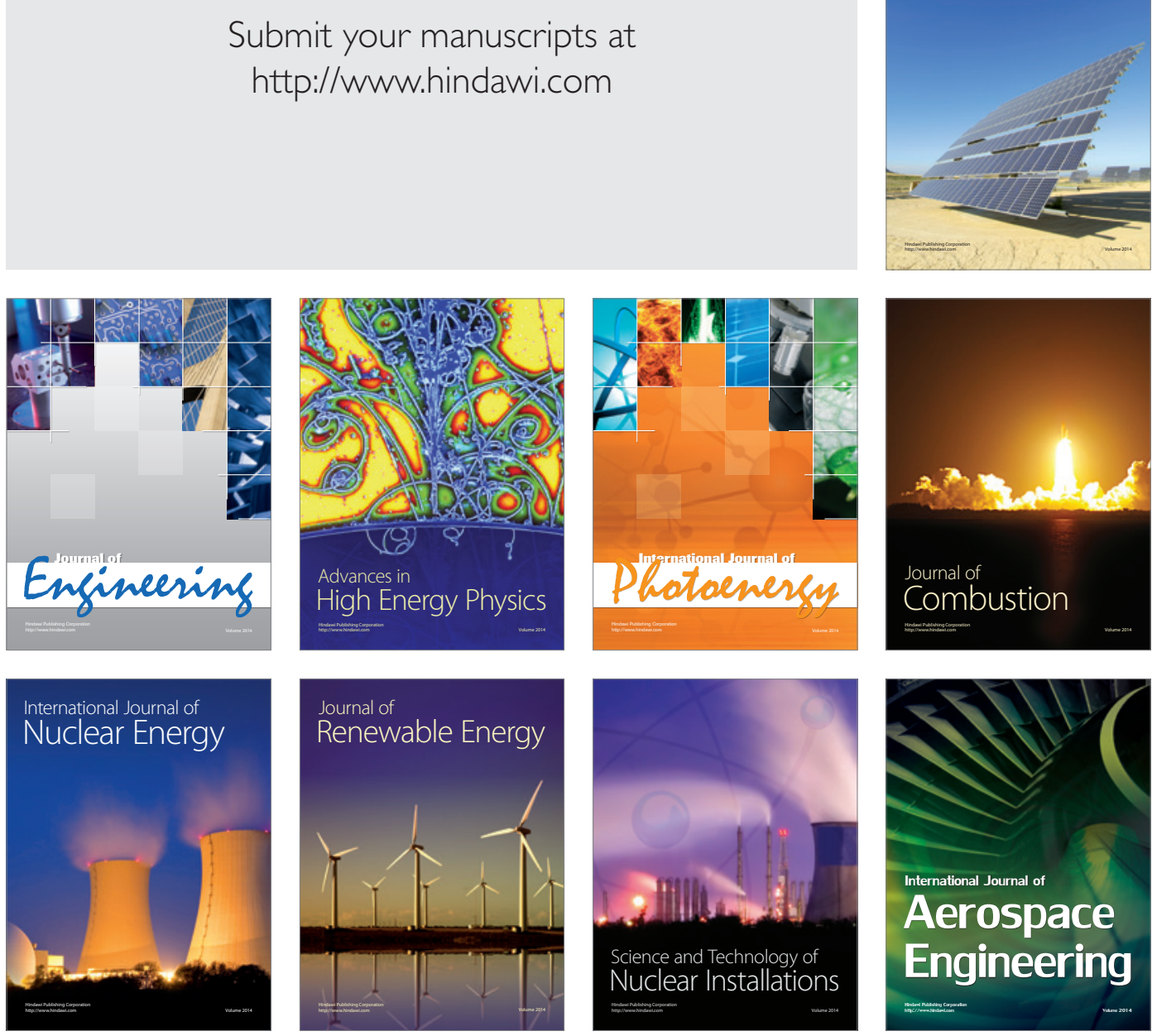